\title{
Evidencing the impact of widening participation access programmes for under-16s: Assessment within the Higher Education Field Academy
}

\author{
Carenza Lewis, University of Lincoln
}

\begin{abstract}
This paper considers the role of assessment within widening participation schemes, particularly those targeting learners under the age of 16 which can struggle to demonstrate impact when university may be three or four years ahead. The Higher Education Field Academy (HEFA) is a cross-curricular scheme in which 13-15-year-old learners work in small, mixed-school teams to complete a two-day outdoor investigation before spending a third 'taster day' in university when they learn about applying to university and analyse their investigation data before writing an assessed project report. HEFA aims not only to raise academic aspirations, but also to equip learners to fulfil those aspirations by enabling them to develop transferrable skills which support their learning and boost confidence. This paper explores how HEFA's design, assessment framework and feedback protocols have been developed in order to help achieve these aims, and how they can identify direct links between intervention and outcomes. It concludes that collecting a detailed, robust elicitation of the attitudes, knowledge and skills that participants gain from widening participation activities, and feeding this back to learners as well as organisers, enables learners to make better use of this gain and evidences the benefit to learners and society.
\end{abstract}

\section{Introduction}

There exist in the UK a large number of 'widening participation' (WP) initiatives intended to increase rates of progression to tertiary education from areas and demographic groups which are currently under-represented. This reflects the continuing need for universities to improve access to higher education (HE) as, despite considerable progress in recent decades in reducing social differentials in UK HE progression rates (Milburn, 2012), the percentage of state-educated young people who progress to HE (48\%) is still smaller than for those who are privately educated (60\%) (DOE, 2014, 11), while large pockets of very low rates of progression to HE remain in many rural and formerly industrial areas (HEFCE, 2013, 27-30; HEFCE, 2016). Most recently, the need to focus on supporting student learning into and beyond the life-cycle of the university course has been highlighted (OFFA, 2015, 2-3), as has concern that an evolving 'hourglass society' may in the future reduce the options for people from poorer backgrounds to progress to university (Stuart, 2012, 133-151). 
There is a growing body of literature exploring the aims and outcomes of WP initiatives (e.g. Thomas, 2001; Bekhradnia, 2003; Greenbank, 2006; Boliver, 2011; Stuart, 2012; OFFA, 2014; McCaig, 2015), which have developed and adapted in response to changes in government policy over the last 20 years (e.g. Dearing, 1997; Browne, 2010). Currently, WP strategies in the UK fall into four broad categories: Access, Student Success, Progression and Financial Support. The last three categories focus on supporting students once they are engaged in tertiary education, while 'Access' initiatives target pre-HE cohorts and encompass a range of activities intended to raise 'awareness, aspiration and attainment' (OFFA, 2015, 10) regarding postsecondary education. These typically include visits by HE staff and students to schools and colleges; visits by pre-HE cohorts to tertiary educational institutions for open days; participation by pre-HE cohorts in masterclasses, taster days and summer schools run by HEIs; and provision by HEIs of mentoring and after-school tuition schemes.

Literature examining the role of WP 'Access' (WPA) schemes has given considerable attention to problematizing and evaluating programme 'beginnings' (recruitment, targeting) (e.g. HEFCE, 2015; McCaig, 2015; Rainford, 2016) and 'ends' (learner progression, educational destinations) (Passy and Morris, 2010; HEFCE, 2013; OFFA, 2014; OFFA, 2015), the latter more recently extending beyond matriculation to encompass HE student retention and degree completion (Thomas, 2012; Budd, 2016). Less attention, however, has been given to the core 'middle' part of WPA activities, including what learners actually do and are expected to learn when they are taking part, and what impact this has (e.g. Basu, 2008): this risks losingsight of the precise mechanisms by which desired WP outcomes can be achieved (or, indeed, missed) (Harrison et al 2015). The diagram below sets out the three part lifecycle of WPA schemes. 
Figure 1: Diagram of the WPA scheme lifecycle

\begin{tabular}{|c|}
\hline $\begin{array}{c}\text { Beginning: } \\
\text { Setting up the WP } \\
\text { activity }\end{array}$ \\
\hline -Aims (reach, desired \\
impact) of WP activity \\
are established. \\
- Format of WP activity \\
agreed \\
- Method for identifying \\
priorty \\
schools/learners are \\
developed. \\
-WP activity is \\
promoted to schools \\
and learners \\
-Issues (actual or \\
potential) negatively \\
impacting on learner \\
are addressed. \\
- Learners are enrolled \\
onto WP programme. \\
\end{tabular}

\begin{tabular}{|c|}
\hline $\begin{array}{c}\text { Middle: } \\
\text { Delivering the WP } \\
\text { activity }\end{array}$ \\
\hline - Learners take part in: \\
- Visits by HE staff and \\
students to schools \\
and colleges; and/or: \\
- Visits to universities \\
and colleges for open \\
days; and/or: \\
-Masterclasses, taster \\
days and summer \\
schools led by HEls; \\
and/or: \\
-Mentoring and after- \\
school tuition schemes \\
delivered by HEls. \\
\end{tabular}

\begin{tabular}{|l|}
\hline \multicolumn{1}{|c|}{ Ends: } \\
Evaluating the WP \\
activity
\end{tabular}

Reflecting recent observations that

'...to evaluate an access initiative, data should be collected not only about the outcome(s), but also about the effect of the intervention(s) on the determinant(s) and about the relationship between the determinant(s) and the outcome(s)' (Childs et al, 2016, 3), this paper focusses on the 'middle' part of the WPA scheme lifecycle, analysing and contextualising the content, assessment and immediate impact of the Higher Education Field Academy (HEFA). HEFA is a carefully structured research-engaged learning programme which includes robust assessment on four levels: reaction (from learners and school staff), learning, behaviour and results (Kirkpatrick, 1994), and has involved more than 5000 teenagers over more than ten years. Such a large and robust dataset thus allows more general consideration of how the impact of WPA schemes can usefully be assessed, and why. In exploring how personal and learning outcomes can be assessed, this paper also contributes to wider debates about approaches to evaluating educational programmes (e.g. Watkins et al, 1998, Praslova, 2010).

\section{Aims of the Higher Education Field Academy}

HEFA aims to raise academic aspirations amongst disadvantaged stateeducated UK students, including learners with no university-educated close family members, learners living in areas with low rates of progression to 
university, learners attending secondary schools with poor GCSE performance and/or from which few students progress to university, learners who are being looked after by local authorities, learners who receive free school meals and learners identified by their schools as being in particular need of support. HEFA targets learners in school years 9-10 (13-15-years old), an age when learners can begin to disengage from education but which is often overlooked by WP provision, much of which focusses on over-16s. Young people's experiences are however critical to the likelihood of them progressing to higher education (Reed et al, 2007, 15-16) and 13-15 is an age when there is time for learners to get themselves (back) on track to fulfil their potential at GCSE.

HEFA was devised by Carenza Lewis in collaboration with Aimhigher ${ }^{1}$ Cambridgeshire and Peterborough (Lewis, 2014b) in 2005, and from its inception, was intended to exceed the conventional WPA aims of inspiring and informing (HEFCE 2007; Passy and Morris, 2010) by also instilling skills for life and learning in participants which could boost self-confidence (Attwood, 2007) and educational achievement (Lewis, 2007, 136-7). That this is an important issue for WPA is reflected in recent research indicating that experience at Key Stage $3^{2}$ and performance at Key Stage $4^{3}$ is an crucial factor in progression to higher education (Reed et al, 2007; Childs et al, 2016), but that improving performance is typically disregarded as an aim by WP programmes (Harrison et al, 2015, 12-13), despite the sustained engagement offered by summer schools and taster weeks being seen as particularly valuable in this respect (Harrison et al, 2015, 15).

Since 2005, HEFA has run under Lewis' direction from the University of Cambridge (since 2015 at the University of Lincoln) with the universities of Bedford, East Anglia, Essex, Hertfordshire, Lincoln, Newcastle, Sheffield and Suffolk involved for varying periods of time in a range of capacities. From 2005-11, HEFA formed part of Aimhigher's programme of generic summer schools, which were required to run over two or more residential or non-residential days and to give learners experience of university life and learning (HEFCE, 2005; Hatt et al., 2007; HEFCE, 2007; HEFCE, 2012).

Until 2011 HEFA was funded by Aimhigher (Bedfordshire, Cambridgeshire and Peterborough, Essex, Hertfordshire, Norfolk and Suffolk); while since 2013, following Aimhigher's closure in 2011, HEFA has been funded by the University of Cambridge as part of its access agreement with OFFA.

A core principle underpinning HEFA is that enabling learners to develop knowledge, skills and confidence (to help them achieve their raised academic aspirations) can be achieved through taking part in, and making a valuable contribution to, university research (Lewis, 2007, 136-7). This principle is notably at the heart of 'Student as Producer' (Brew, 2006; Neary and Winn, 2009). The research involved could in theory be on any topic, as long as the skills gained are transferrable, and the learning does not require familiarity 4 
with GCSE ${ }^{4}$ subjects which some students study and others do not (as this would differentiate the learning baseline and potentially the capacity for benefit).

On HEFA, the research discipline involved is Archaeology, a subject chosen for a number of reasons. Firstly, Archaeology is not available at GCSE in the UK, therefore no HEFA learners can be unfairly advantaged or disadvantaged by which GCSE subjects they are studying as none will be studying Archaeology. Secondly, the widespread distribution of archaeological sites in the British landscape means that it is possible for learners to find useful research data in almost any location. Thirdly, archaeological fieldwork involves a wide range of academic, cognitive, personal and practical skills. Consultation with Aimhigher Cambridge (with Peterborough Unitary Authority) link schools during HEFA's development phase indicated that archaeological excavation would be a popular choice of activity with learners. This is due to its being prominently featured on television and to it being appealingly (for teenagers) unconventional.

Once it was established that archaeological fieldwork could be the focus of research-engaged learning, a programme was devised for HEFA in which learners would complete small 'test pit' excavations in selected rural towns and villages, with learners' discoveries and observations used to reconstruct the long-term development of the settlement in question. This approach had previously been convincingly shown to contribute effectively to academic research in a small number of historic rural communities (Cooper \& Priest, 2003; Gerrard and Aston, 2007; Lewis, 2003), and related to an area of enquiry in which Lewis had an established track record (Aston and Lewis, 1994; Lewis et al., 1997) and was keen to extend into new areas (Lewis, 2007, Lewis, 2014a; Lewis, 2016). The research methodology requires the same rapid process (excavation of a $1 \mathrm{~m}^{2}$ trench) to be carried out repeatedly, perfectly suiting it to Aimhigher's requirements for standardised scalability; while focusing the excavation within villages, farms, hamlets and small towns means that suitable excavation sites can be found wherever needed, which can otherwise be problematic (Knowles, 2012, 65-6; Dhanjal, 2005: 39). This inhabited location also helpfully provides more opportunities for social interaction between HEFA learners and residents than a deserted archaeological site would.

Figure 2: HEFA learners working on test pit excavations in Riseley (Bedfordshire) and Little Hallingbury (Essex) 


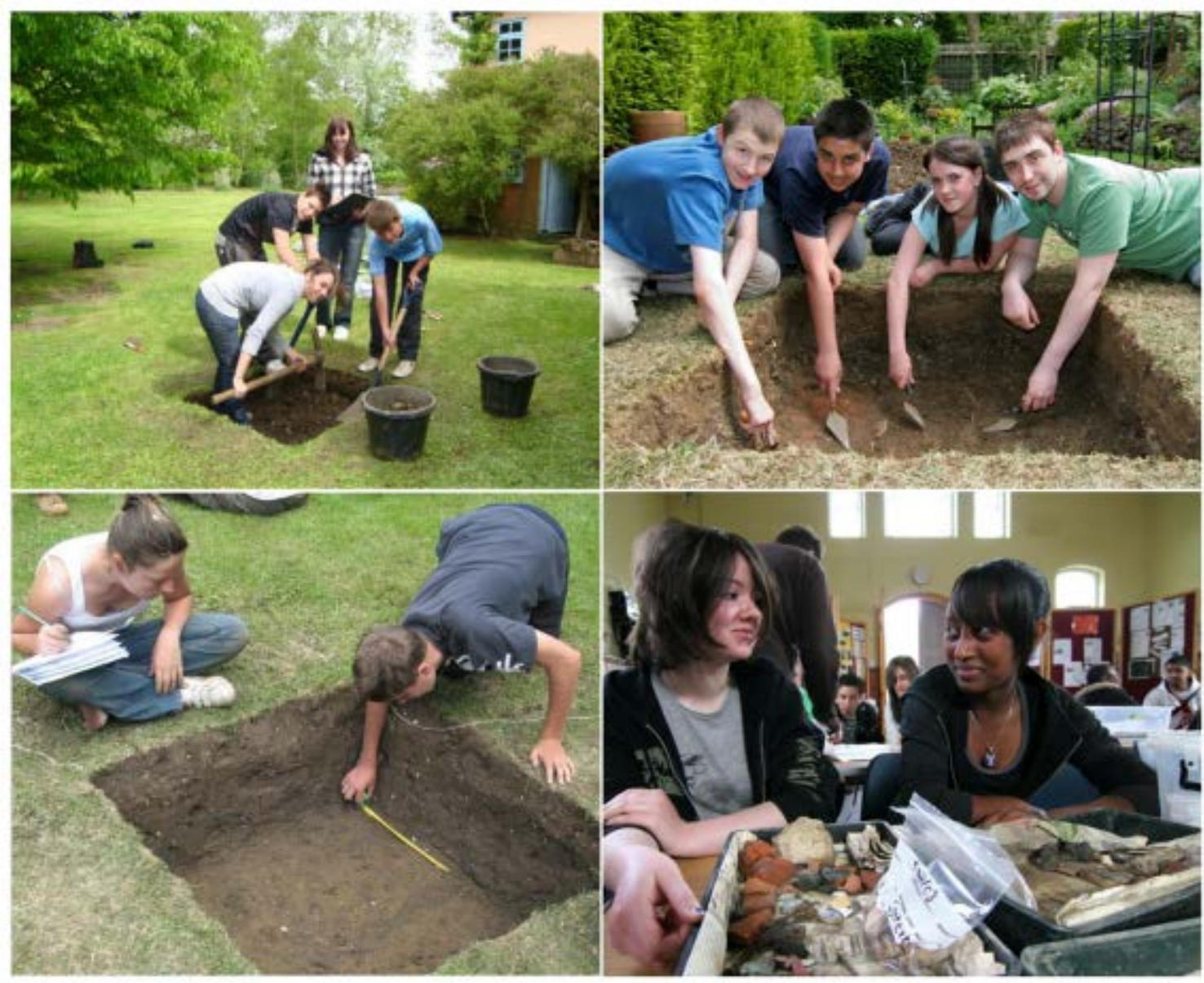

Each HEFA follows the same structure (Lewis, 2007, 137-9), involving up to 48 learners from up to 12 different schools over three days. After an initial whole-group briefing on excavation aims, methods and protocols, learners work for two days in mixed-school groups of three or four to complete one of up to 12 test pit excavations in the same historic settlement. Supported by a handbook, they measure out a $1 \mathrm{~m}$ square, survey and map its location, remove turf, excavate soil in $10 \mathrm{~cm}$ spits, sieving spoil and retaining all manmade finds until they reach the bottom of the archaeological deposits when they backfill the pit and replace the turf. They record observations in a pro forma booklet which includes their drawings and photographs of each layer before excavation. Learning mostly adopts a constructivist approach (Hein, 1998; Piaget, 1963) with written materials supported by hands-on demonstrations and discussion with experts, recognising that different learners prefer different learning methods (visual, auditory, kinaesthetic) (Gardner, 1983). After completing their excavation, learners spend a third day indoors at an HEI, finding out how their discoveries contribute to research, touring and dining in student halls and participating in a workshop about university. Subsequently, at home or back in school, learners prepare a written report on their excavation using the records they themselves have kept. The aim is that learners will be able holistically to develop a range of cognitive, communication and writing skills necessary for success in education in a way which boosts their educational self-confidence and success more effectively 
than taking part in passive observation or replicative activities.

\section{Assessment methods}

The impact of HEFA was closely monitored from the outset (Lewis, 2007, 136-9). Data is collected on learners' background, their responses to HEFA and their performance, using application forms, written and verbal 'before and after' feedback forms (completed by learners and accompanying school staff) and evaluations by team supervisors. HEFA application forms record learners' home post-code, school name and the educational background of close family members along with the learner's 'personal statement' giving their reasons for wishing to attend HEFA, and a school statement confirming the learner's suitability with reference to funders' priorities. Optional data on personal and family background is usually provided by families and/or learners. At the beginning of the first day learners answer questions about their attitudes to post-16/higher education and their expectations of HEFA, and at the end of the third day they complete a longer form, rating their experience of HEFA and assessing the impact it has had on their attitudes to their education and abilities. Assessment of learners' written reports and their practical performance are fed back in a final letter to each learner.

Assessment of learner performance was already firmly embedded within HEFA when in 2009 the opportunity arose to refine the skills-assessment framework in an applied research collaboration with Cambridge Assessment (Johnson \& Lewis 2013). This was timely as the outcomes could by then be seen in a programme which had grown from around 100 participants in 2005 to more than 400 per annum by 2008 , creating both the capacity and the need to ensure the assessment process was delivering the maximum benefit as HEFA was scaled up. ${ }^{5}$ The aim was to ensure that learners were maximally aware of the learning they had achieved on HEFA, so they could use their achievements to their best advantage in the future. Learners in school year 9 or 10 are mostly unfamiliar with having their performance scrutinised by an external body, and have little or no experience of receiving feedback from this process. HEFA thus not only gives learners an indication of their strengths and weaknesses, but in more general terms also introduces them to the process of external assessment for which they will need to prepare in GCSE and A Level. Giving learners the opportunity to self-assess and providing them with feedback on their supervisor's assessments helps demystify the assessment process, making it more understandable and less intimidating. Clearly linking the skills learned to the behaviours used to demonstrate these skills increases learners self-belief in their achievement and thus in their abilities.

The principles and processes by which the new assessment framework was developed have been detailed elsewhere (Johnson and Lewis, 2013) but can usefully be reviewed here. With four years' experience of running HEFA, by 
2009 the skills developed by learners were easily elicited by Johnson and Lewis, and these were then grouped into three broad categories: writing skills, technical skills and 'soft' personal, learning and thinking skills (often referred to as 'PLTS') (National Curriculum, n.d.). Each category includes a number of sub-categories, which are themselves subdivided into different behaviours. Thus the 'writing skills' category includes report structuring (ordering information to achieve a comprehensible narrative thread); research skills (including sourcing and correctly referencing relevant background information); writing skills (including spelling, punctuation and grammar as well as use of a cogent and engaging writing style); and IT skills. The 'technical skills' category includes those used widely in research and workbased projects: data collection and processing; measuring and recording; observing health and safety guidelines. Personal, learning and thinking skills ('PLTS') include verbal communication (presenting information and engaging in debate); structured working (following set methods, keeping work area tidy); creative/critical thinking (interpreting finds and devising solutions to problems); reflective learning (evaluation of own and team performance well as responding to feedback); working with persistence (maintaining focus and a positive attitude) and team working (fulfilling own role, supporting other team members, demonstrating leadership skills).

Having identified and categorised the skills used on HEFA, the next step was to develop a means of assessing them. Assessing written work is a fairly routine activity for educationalists (although, as noted above, not often used in conjunction with WPA activities), so developing a framework for assessing written reports submitted by HEFA learners was straightforward. Devising a means for validly assessing practical and personal skills was initially more difficult, because unlike writing skills these are not assessed within the school curriculum in the transferrable, inter-disciplinary terms needed for HEFA so there were no models to base the process on.

The final HEFA framework used the same basic process to assess skills in all three categories: range descriptors specific to HEFA against which each learners' observed performance can be matched. Each descriptor is a concise, objective description of behaviour expected of a given task at a given level, and each skill sub-category has three descriptors: high, middle and low standard. In each skill sub-category, the assessor identifies which descriptor standard matches most closely with observed performance, then assesses the learner's position within that range (also as high, middle or low). Top of the range for each skill is thus level nine and the bottom is level one.

Figure 3: Extract from the HEFA assessment framework showing range descriptors for skill sub-category Structured Working (E1) 


\begin{tabular}{|c|c|c|c|c|}
\hline & $\begin{array}{l}\text { Structured } \\
\text { Working }\end{array}$ & & & \\
\hline E1 & $\begin{array}{l}\text { Plan and } \\
\text { carry out } \\
\text { scheme of } \\
\text { work in } \\
\text { structured } \\
\text { manner and } \\
\text { within } \\
\text { required time }\end{array}$ & $\begin{array}{l}\text { This individual has } \\
\text { shown minimal } \\
\text { interest in planning } \\
\text { or carrying out the } \\
\text { required tasks in the } \\
\text { correct order or } \\
\text { within a reasonable } \\
\text { timescale, taking } \\
\text { either far too much } \\
\text { or far too little time } \\
\text { on tasks. }\end{array}$ & $\begin{array}{l}\text { This individual has } \\
\text { used the handbook to } \\
\text { plan and follow the } \\
\text { required work } \\
\text { programme correctly. } \\
\text { With some help he/she } \\
\text { has identified } \\
\text { objectives and planned } \\
\text { tasks clearly. Task- } \\
\text { flow has been planned } \\
\text { and managed; } \\
\text { progress has been } \\
\text { monitored effectively. }\end{array}$ & $\begin{array}{l}\text { This individual has } \\
\text { used the handbook } \\
\text { without prompting } \\
\text { to pro-actively plan } \\
\text { and help drive } \\
\text { through an effective } \\
\text { programme of } \\
\text { work. He/she has } \\
\text { identified objectives } \\
\text { and defined tasks } \\
\text { clearly and has been } \\
\text { pro-active in } \\
\text { monitoring progress } \\
\text { and ensuring tasks } \\
\text { are completed on } \\
\text { time. }\end{array}$ \\
\hline
\end{tabular}

In order to maximise opportunities for learning, all the range descriptors are shared with learners so they can assess their own performance, with the intention that this will increase learners' awareness of the skills they can develop and what they need to do to achieve high marks. Supervisors and learners alike are asked to discuss the assessment process during the day and make a provisional, formative assessment at the end of the first day which will allow learners to sustain or improve on their initial achievement during day 2. A final summative assessment of practical and personal skills is made by supervisors and learners at the end of the second day. The project report which learners write after they compete HEFA is assessed using a similar system of range descriptors.

\section{Feedback to learners}

Once all stages of HEFA participation, assignment submission and assessment are complete, learners are sent a certificate of attendance along with a letter thanking them for their participation and contribution to university research into historic settlement development, supplemented by a detailed written analysis of their performance. This latter part of the letter explains, for each of the main skill sets, what the skill in question is and why/how it is valuable in education and/or employment, and (using software to insert text according to the supervisor's marks) provides the learner with an account of how they performed, in language that they could use in applications for jobs and university places (see Figure 4).

Figure 4: Extract from the letter learners receive after they complete HEFA showing the contextualising text (in italics) and personalised report (below) for a learner who gained marks of 8/9 and 7/9 in the two 'Structured Working' subcategories 
ii) Structured Working (Your Mark $=88.89 \%$ )

An ability to plan, carry out and complete a programme of work effectively and within the time available, leaving no loose ends, requires efficiency and time management skills, and is vital, whether used to ensure GCSE coursework is handed in on time or that the construction of a new stadium is ready for the first match of the season. On HEFA, you demonstrate skills in time management and structured working by carrying out all the tasks in the correct order, ensuring the site is tidy at all times, by finishing within the allotted time and leaving your site neat and tidy.

You have shown considerable interest in pro-actively planning or carrying out the required tasks in the correct order and within a reasonable time-scale. You needed no encouragement to ensure that the site was as tidy as possible and to cleaning and storing equipment appropriately.

The accompanying letter reminds learners that the skills being discussed are ones they should remain aware of and can use when preparing job applications or personal statements for UCAS ${ }^{6}$.

These letters thus effectively constitute a personal reference for every HEFA learner which they can keep as a reminder of what they are capable of. The aim is that for learners, the assessment and reporting process develops conscious awareness of competences, which helps boost achievement and self-confidence as well as helping them prepare applications to academic institutions or employers. The explicit link between the skills which are being identified, the behaviours which learners have used to demonstrate those skills, and the written account theyreceive, means that learners recognise the validity of the assessment and can therefore feel confident about the skills they have.

\section{Targeting HEFA}

Application data and supervisor assessment data is collected on every HEFA attendee and more than $80 \%$ submit written feedback forms and/or written assignments. Analysing these has allowed HEFA's impact on learners to be closely monitored, week by week and year on year, over the sustained period of time for which the programme has now been running.

Feedback data shows that HEFA is very successful in reaching target cohorts and in impacting positively on them. While funded by Aimhigher, more than $90 \%$ of learners came from families where no parents/primary carers had attended university, with most of those who were in paid employment engaged in manual or semi-skilled work. A detailed account of the adjustments required after Aimhigher's closure in 2011 is beyond the scope of this paper, but post-2011 targeting of HEFA using POLAR ${ }^{7}$, GCSE league table and school 'added value' data to identify priority schools ensured that in 2013, 81\% of the 52 participating schools and $77 \%$ of 529 learners were priority/high priority, with most of the remainder being 'beacon schools' who helped with local recruitment. Ethnicity was selfidentified by learners, and comparison of HEFA participant data showed a broad match with census data. In 2009, for example, 15\% of HEFA attendees identified as non-white compared with $10.7 \%$ non-white minority 
ethnic in East Anglia in 2001, showing this sector of the population to be proportionately well-engaged with HEFA. $4 \%$ of attendees reported a disability (mostly relating to ADHD). Less than 1\% had previous experience of excavation, although a substantial minority expressed (in various ways) an interest in History.

\section{The Impact of HEFA}

Data pertaining to the impact of HEFA have been presented in detail elsewhere (Lewis 2011; Lewis 2014b), but can usefully be summarised here as it is of course highly pertinent to the argument that the robust assessment system used on HEFA achieves its aims of raising aspiration, boosting confidence and developing skills. Feedback from more than 2,000 HEFA learners by 2011 (Lewis, 2011; 2014b) and more than as many again between 2012-16 (Lewis, 2014c; Lewis, 2015) consistently shows the impact HEFA has on the number of learners intending to apply to university: in 2005-11 the number definitely considering university rose by $26 \%$ when 'before and after' figures are compared, with $78 \%$ of all students confidently seeing higher education part of their future after HEFA and only 4\% rejecting this (Lewis 2014b, 303-4). In some areas the impact is even higher: in October 2015 in rural Lincolnshire (a county where HE progression drops in some areas below $10 \%$ ), the number of learners intending to apply to university was raised from $60 \%$ to $95 \%$. Equally important is the impact HEFA has on attitudes to university, and here feedback shows that around $84 \%$ of participants in 200511 felt more positive about going to university after HEFA than before (Lewis 2014b, 303-4).

Figure 5: Caption: HEFA learners celebrate their test pit excavation in Coddenham, Suffolk

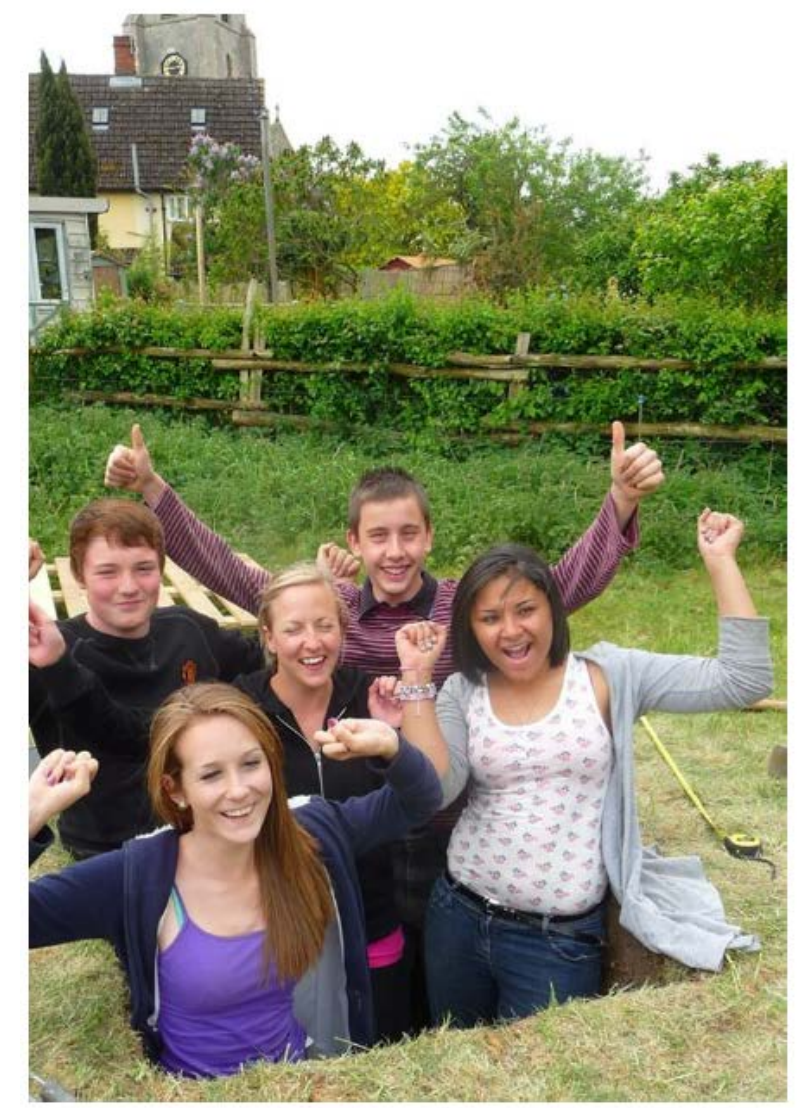


Feedback is also collected on learners' attitudes to 16-18 education, a vital first step in making progression to university a real possibility: responses from more than 2000 respondents in 2005-11 showed that after HEFA, 79\% felt more positive about staying in education after year 11 (Lewis, 2014b, 306). Feedback from hundreds ${ }^{8}$ of school staff also consistently rates HEFA extremely highly (Lewis, 2011, 28-9), and this is materially substantiated by the considerable investment by scores of schools of thousands of hours of staff time in HEFA. Since the new assessment framework was introduced, the submission rate for written assignments has risen from c. 39\% of learners (Lewis, 2014b, 307) to over 70\% (Lewis, 2014c; Lewis, 2015).

HEFA's longer-term impact is tracked at the end of year 11, one or two years after most learners have taken part in HEFA (Lewis, 2011, 30-33; Lewis, 2014, 310-11). Attitudes to HEFA remain very positive in retrospect, and $80 \%$ of former HEFA respondents report they are planning to continue in education and study ' $A$ ' Levels (the conventional route to university). This percentage is very close to that indicated in feedback immediately after HEFA, and suggests this figure is reliable. Intended university subjects range (alphabetically) from Accountancy to Zoology with Medicine and Natural Sciences being the most popular subjects (Lewis, 2014b 310-1), showing that HEFA succeeds in raising aspirations across the widest spectrum of subjects (HEFA has never been about recruiting specifically to Archaeology).

Tracking learners beyond two years, i.e. into sixth form and beyond, is both more difficult and more contentious. It is difficult because learners often move institutions after GCSE and lose their unique educational identifier number at the end of compulsory education; while further down the line, accessing person-specific destination data from UCAS is problematic. It is contentious because, as the elapsed time between the intervention (e.g. HEFA) and the outcome (e.g. post-18 destination) increases, it is more difficult to link outcome to intervention, as any individual intervention may have been one of many factors influencing learners' decisions: hence the value of longer-term tracking is not proven. It is anecdotally noted, however, that school staff attending HEFA year on year, or who are involved with collecting tracking responses frequently comment on the enduring nature of HEFA's impact on learners' attitudes and behaviour and report that the great majority of HEFA veterans do fulfil the intentions to progress to HE which they express at the end of HEFA and in subsequent tracking (Stone, 2013; University of Cambridge 2013, Contact 2).

While it will thus always be difficult to demonstrate beyond all doubt the link between post-18 educational destination and a WP intervention which took place four or five years previously, the rigorous assessment framework used on HEFA certainly is, as intended, able to demonstrate its impact on learners' attitudes and skills (Lewis, 2011, 18-22; Lewis, 2014b, 306-7). This in itself is important as this will help them aspire and achieve at school and thus 
support HE progression (Reed et al, 2007; Childs et al, 2016). Figures from HEFA supervisor assessments (and HEFA learner's self-assessments) are recorded for each year since the Johnson/Lewis framework was introduced in 2010. This not only shows how effective the intervention is, but also how consistent. Comparing figures from 2009-10 (Lewis, 2011, 18-22 \& figs 1016) and 2012-13 (Lewis, 2014b, figs 8-11) shows that in 2012-13, 77\% of learners considered that they had developed skills in verbal communication categories, very similar to $76 \%$ in $2009-10$. In $2012-1387 \%$ felt their structured working skills had been developed (80\% in 2009-10); $79 \%$ in creative thinking categories (78\% in 2009-10); $78 \%$ in reflective learning categories (76\% in 2009-10); 86\% in persistence categories (83\% in 200910 ) and $87 \%$ in team working categories (87\% in 2009-10). It is interesting to note that learners' self-evaluation tallies closely with the marks given by supervisors (Lewis, 2014b, 306-14). This all shows that learners are acquiring an awareness of their competence which is not only conscious but also valid, across the wide range of transferrable practical, personal and written skills that HEFA encompasses.

\section{Factors underpinning HEFA's impact}

The Johnson/Lewis framework for assessing learning, impact and outcomes on HEFA include a comprehensive range of clearly elicited criteria for recording and evaluation encompassing the four conventional levels: reaction, learning, behavior and results (Kirkpatrick, 1994, Praaslova, 2010). This delivers a robust corpus of data which helps identify those factors which are important in enabling HEFA to succeed as a WP activity in the way it clearly does, which are as follows.

Firstly, learners enjoy the experience. While this is not unique to HEFA, it is important because enjoying HEFA creates a positive association with higher level learning. 91\% of participants rate HEFA as excellent or good in feedback, despite (or possibly because of) the challenging nature of the activities they are expected to undertake. Free-text comments by learners bubble with enthusiasm (codes indicate initials and year):

'It was brilliant fun and I feel like I've learnt so much. I would recommend this to anyone!' (GM2010) (Lewis, 2014, 303);

'Thank you so much for the opportunity of working with the people at HEFA. It has been amazing and an experience that I will never forget.' (LG2010) (Lewis, 2011, 27);

'It was fun and enjoyable and you don't need to like archaeology to have a go. I think everyone should take part.' (SS2015) (Lewis, 2015, 8); 
'LOVED IT ALL!!! It was the greatest experience of my life.' (CDK2010) (Lewis, 2011, 26).

Similar attitudes are expressed in feedback from hundreds ${ }^{9}$ of learners each year, with the enthusiasm apparent immediately after HEFA sustained in retrospective comments made on longer-term tracking forms (Lewis 2011, 31-3) such as:

'It was fantastic. A good experience and would really love to do it again.' (AM2010) (Lewis, 2011, 32);

'The field academy was really enjoyable and it gave me the confidence that I needed.' (LB2010) (Lewis, 2011, 32).

School staff are equally positive, (although usually in more measured tones), emphasising the value of combing fun, challenge and learning:

'The students loved the fact that they were doing something not done before and recording something that will be used by the university. They have gained new skills, more self-reliance and motivation. For many it's really helped inspire or confirm for them that university is what they want to do.' (MR2015) (Lewis, 2015, 7).

It is striking to read staff noting that amongst their learners, HEFA out-ranks alternatives on offer which might be expected to be much more popular, such as trips to Alton Towers (Lewis, 2014b, 301) or Thorpe Park:

'An amazing experience. On the Thursday the school was doing a rewards trip to Thorpe Park. A couple of students were thinking about doing the reward trip instead but after Day One decided they'd rather complete the HEFA course.' (JF2010) (Lewis, 2011, 29).

HEFA demonstrably provides learners with a positive experience which is able to generate positive attitudes to higher education.

When considering why HEFA is so popular, four points stand out in learners' comments: learning, authenticity, diversity and sociability (Lewis, 2011, 247; Lewis, 2014b, 315-8). Learners frequently comment on how much they have learnt:

'I have learnt so much from this project and had such a good time. Overall, it has been an amazing project and I'm so happy that I was able to attend.' (AC2009) (Lewis, 2011, 26); 
'Learning something new' is an aspect of HEFA which is ranked consistently highly (Lewis, 2014, fig 13). Feedback also shows that learners relish the challenge of undertaking and managing something which is authentic: they appreciate being entrusted with a task which has not been dumbed down, which is important, which they know has never been done before and can never be repeated and will produce new finds which they know will never have been seen before:

\begin{abstract}
'It was a highly enjoyable experience discovering things centimetres under my feet. It opened my eyes discovering things that have not been touched in hundreds of years. Thanks.' (LW2010) (Lewis, 2011, 27).
\end{abstract}

They also enjoy doing something new which involves a variety of different activities which they have not done before:

'(What I enjoyed most was) the fact it was something new in a new place, different from our normal surroundings.' (DA2010) Lewis, 2011, 27).

While many learners are initially doubtful about the prospect of working in mixed-school groups with people they have never met before, end-of-course feedback consistently ranks social aspects (meeting new people, working in teams) highly and learners' free-text comments frequently refer to this:
'At first I thought I would hate it, but surprisingly, I enjoyed it. It was a good challenge and I enjoyed meeting new people. It has given me new skills I will never forget and helped me to make some new good friends.' (HS2009) (Lewis, 2011, 25).

Literature around competence-based learning (Eraut, 2000) offers further insights into how and why HEFA achieves its impact on learners. Competent performance integrates different types of knowledge and skills, and HEFA requires and recognises holistic use of a range of skills, integrating existing and newly acquired skills, as well as public and private knowledge, in a very different way to most schooled learning and assessment. On HEFA, for example, learners can contribute their recollection of the excavation process gleaned from reading the handbook (public knowledge) with knowledge of how to use earth-moving equipment gained from helping family members with gardening (private knowledge), while also deploying tacit 'PLT' skills such as being able to motivate other team members or use humour to diffuse group tensions. The HEFA environment is rendered particularly effective for learning as it not only values all these various skills but also enables them to be carried out holistically in an activity which does not separate out one learning medium (e.g. reading a text) from others (carrying out practical 
work, developing an idea), maximising opportunities for learning 'transfer' (Aarkrog, 2011; Shuman et al 2005; Johnson and Lewis, 2013, 181-2). This is evident in learner comments such as:

'...it was good to learn about the history of a settlement and feel like I am actually helping to discover new things and learn how archaeology works. I also feel I've gained more confidence by working with other people I've never met and teamwork and leadership skills.' (KC2009) (Lewis, 2011, 24);

'I enjoyed doing something new and different and creating for myself a new experience and using my creative thinking skills to guess what objects were.' (BG2015) (Lewis, 2015, 8)

Feedback is another factor identified as affecting learning transfer (Jørgensen, 2004; Laker and Powell, 2011, 17; Johnson and Lewis, 2013, 183), and as has been demonstrated in this paper, feedback is embedded throughout HEFA. At the most direct level, the tangible nature of the excavations provides a very visual measure of achievement at every stage (e.g. how deep the pit has become) which generates satisfaction and builds confidence, which in turn reinforces positive engagement (Johnson and Lewis, 2013, 180):

'My team worked really hard throughout both days, and despite only being a team of three, got down to 80cms! It is wonderful to be able to talk to the professionals and yet let the students manage the whole project themselves' (PT2009) (Lewis, 2011, 28) (comment from a member of school staff).

Constructivist approaches to learning and formative assessment during HEFA enable learners to take informed responsibility for their own progression, while at the end of the course, HEFA's transparent assessment process and intelligible reporting of performance data contextualises achievement so it is meaningful and believable for learners and thus useful for them as their lives move forward:

'I think that I have gained valuable, transferable skills which I will be able to apply to future work. Also, learning about university life has been a great experience!' (TC2014) (Lewis, 2014c, 7) 


\section{Conclusion}

HEFA was devised according to the principle that helping young learners develop skills and attitudes that will help them in life and learning would be an effective way of building knowledge and confidence which in turn enhance the capacity of learners to fulfil their raised aspirations. The role of assessment in this process is critical because it provides evidence to show how knowledge, skills and attitudes have been affected. This is essential, not just so that WPA activity providers can gauge the success of their programmes, but more importantly (because this is at the heart of what WP programmes are trying to achieve), so that learners have a conscious awareness of what they have gained which they can recognise, and thus believe in, and thus use to their best advantage.

This paper aimed to explore how HEFA, as well as delivering the more conventional WP aims of informing and inspiring young people, also instils and assesses transferrable skills which are essential to success in education and work. Rigorous 'before and after' evaluation shows that HEFA has strong positive impacts on learner aspirations and attitudes to learning as it informs, inspires and upskills. Using an assessment framework devised in collaboration with education assessment professionals gives learners a valid, credible measure of the experience and skills they have developed and a secure, enduring understanding of how they can use this in their education and when applying for university places and jobs. HEFA's capacity to demonstrate its impact has been central to its ability to equip and embolden thousands of learners and to survive existential threats when Aimhigher was discontinued to run for more than ten years. It is also potentially able to respond, in its holistic approach to upskilling for employment as well as learning, to newly recognised needs to extend WP support into and beyond the HE lifecycle.

In conclusion, the above analysis of the structure and assessment methods of HEFA shows that the ability to provide a detailed, robust elicitation of precisely what 13-15 year-old learners achieve through taking part in WPA activities, along with a clear explanation of how this will help them in the future, allows the positive impact of WPA initiatives to be evidenced even when interventions are undertaken long before participants could possibly process to tertiary education. Given the difficulty of demonstrating a link between intervention and outcome with this age group, combined with the recognised importance of achievement at GCSE and the evidence that WP learners face disadvantage into and beyond university, it is recommended that more attention should be given to achieving and assessing positive learning outcomes when WPA activities are being designed, assessed and promoted to those who are asked to devote time and/or resources to providing or participating in WPA activities. 


\section{Acknowledgements}

HEFA has been funded by Aimhigher, the Higher Education Funding Council for England (HEFCE), the University of Cambridge, English Heritage and the University of Lincoln as well as numerous smaller local groups and their support is gratefully acknowledged. The universities of Bedford, East Anglia, Essex, Hertfordshire, Newcastle, Sheffield and Suffolk have also provided significant in-kind support. Special thanks are due to Sandy Yatteau, formerly of Aimhigher (Cambridge and Peterborough) who funded and helped develop the first HEFA pilot in 2005 and provided invaluable support thereafter, and also at Aimhigher to Rachel Brown (Essex), Julian Ilman (Suffolk), the late and sadly missed Lorraine Sturman (Norfolk) and Maria Kukhareva (Bedfordshire), as well as their staff and student ambassadors. At the University of Cambridge, Jon Beard and Tom Levinson at the University Admissions Office have provided invaluable support, both financial and professional, especially since the closure of Aimhigher, while Graeme Barker and James Barrett at the McDonald Institute for Archaeological Research have provided much-appreciated in-kind and academic support. Catherine Ranson, Paul Blinkhorn and Jessica Rippengal worked on HEFA in key archaeological roles for many years and special thanks are due to them. The assessment framework which this paper explores was developed in collaboration with Martin Johnson at Cambridge Assessment with support from Tim Oates, also Cambridge Assessment, with invaluable input from Clemency Cooper. Beyond this, thanks are due to literally thousands of people, far too numerous to name individually, including school learners and teachers, owners of excavation sites, and members of the public who helped coordinate projects locally: without their help, HEFA would be impossible.

\footnotetext{
1 Aimhigher was set up in 2004 under the UK Labour government of 1997-2010 by the Department for Education and Skills (DfES) in collaboration with the Higher Education Funding Council for England (HEFCE) in order to raise educational aspirations and attainment amongst young people through activities such as university taster sessions and summer schools. Aimhigher was closed in 2011 by the coalition government of 2010-15, when OFFA (the Office of Fair Access) was created with the aim of ensuring widening participation in higher education would continue.

2 Key Stage 3 (KS3) refers to UK national curriculum learning in school years 7-9, ages 11- 14.

3 Key Stage 4 (KS4) refers to UK national curriculum learning in school years 10-11, ages 14-16 (sometimes including year 9, age 13-14).

${ }^{4}$ GCSEs (General Certificate of Secondary Education) are accredited UK school examinations usually taken by learners in year 11 (age 15-16). Most learners take GCSEs in 6-9 different subjects usually including English, Maths, Science, a foreign language, History and/or Geography and their choice of other subjects.

5 There was also an intention in 2009 that HEFA should achieve independent qualification status, but this was subsequently not possible due to changes in policy at the Department of Education regarding free-standing qualifications at Key Stage 4

6 UCAS refers to the Universities and Colleges Admissions Service in the UK. ${ }^{7}$

Participation of local areas (POLAR) data records the proportion of the UK young population that participates in higher education (http://www.hefce.ac.uk/analysis/yp/POLAR/).

8 Between c.80 and c.130 school staff attend one or more HEFA days each year.

9 Numbers of learners attending HEFA each year since 2007 have varied between 386 (2006-

7) and 668 (2014-15).
} 


\section{References}

Aarkrog, V. (2011) 'A taxonomy for teaching transfer skills in the Danish VET system'. Nordic Journal of Vocational Education and Training 1, 1: 1-13.

Attwood, R. (2007) 'Lack of self-belief deters poor students', Times Higher Education Supplement, 2 February 2007, News section: 3.

Aston, M. and Lewis, C. (1994) The Medieval Landscape of Wessex. Oxford: Oxbow Books.

Basu, P. (2008) 'Extending the Educational Reach of Anthropology? Reflections on London Anthropology Day 2008'. Anthropology Today, 24, 5: 25-26.

Bekhradnia, B. (2003) Widening Participation and Fair Access: An overview of the evidence. Buckingham: Higher Education Policy Institute

Brew, A. (2006) Research and Teaching: Beyond the Divide, London: Palgrave Macmillan.

Boliver, V. (2011) 'Expansion, Differentiation and persistence of social class inequalities in British Higher Education’. Higher Education 61, 3: 229-242.

Browne, J. (2010) Securing a sustainable future for higher education: An Independent Review of Higher Education and Student finance. BIS Report [Online] available at:

https://www.gov.uk/government/uploads/system/uploads/attachment data/file /422565/bis-10-1208-securing-sustainable-higher-education-brownereport.pdf (accessed 11 Oct 2016)

Budd, R. (2016) 'Disadvantaged by degrees? How widening participation students are not only hindered in accessing HE, but also during - and after university'. Perspectives: Policy and Practice in Higher Education, DOI: $\underline{10.1080 / 13603108.2016 .1169230}$

Childs, R. A., Hanson, M. D., Carnegie-Douglas, S. \& Archbold, A. (2016) 'Investigating the effects of access initiatives for underrepresented groups'. Perspectives: Policy and Practice in Higher Education, DOI: 10.1080/13603108.2016.1231720

Cooper, N. and Priest, V. (2003) 'Sampling a medieval village in a day', Annual Report, Medieval Settlement Research Group, 18: 53-56.

Gerrard, C. and Aston, M. 2007. The Shapwick Project, Somerset. Leeds: Society for Medieval Archaeology.

Greenbank, P. (2006) 'Widening participation in Higher Education: An examination of the factors Influencing Institutional policy'. Research in PostCompulsory Education, 11, 2), 199. doi: 10.1080/13596740600769123.

Dearing, R. (1997) Higher Education in the learning society. London: HMSO.

DfE (2015) Destinations of key stage 4 and key stage 5 pupils 2012-13.

Department for Education report, [online] available at 
https://www.gov.uk/government/uploads/system/uploads/attachment_data/file /397946/SFR01-2015_DESTINATION_MEASURES.pdf (accessed 26 Nov 2015)

Dhanjal, S. (2005) 'Touching the Past?' Papers from the Institute of Archaeology 16: 35.

Eraut, M. (2000) 'Non-formal learning and tacit knowledge in professional work'. British Journal of Educational Psychology 70, 1): 113-136.

Gardner, H. (1983) Frames of Mind - The Theory of Multiple Intelligences. New York: Basic Books.

Harrison, N., Waller, R. and Last, K. (2015) The evaluation of widening participation activities in higher education: A survey of institutional leaders in England. Project Report. Bristol: University of the West of England.

[Online]. Available at: http://eprints.uwe.ac.uk/26590 (accessed 12 Oct 2016)

Hatt, S., Baxter, A. \& Tate, J. (2007) Measuring Progress: an Evaluative Study of Aimhigher SouthWest 2003-2006. Higher Education Quarterly, 61, 3): 284305.

Hein, G. (1998) Learning in the Museum. London and New York: Routledge.

HEFCE. (2007) Higher education outreach: targeting disadvantaged learners. Higher Education Funding Council for England guidelines. [Online]. Available at: http://www.hefce.ac.uk/pubs/hefce/2007/07_12/07_12.pdf (accessed 01 December 2015)

HEFCE. (2013) Trends in Young Participation in Higher Education. Higher Education Funding Council for England report. [Online]. Available at http://www.hefce.ac.uk/media/hefce/content/pubs/2013/201328/HEFCE_2013 28.pdf (accessed 26 Nov 2015)

HEFCE. (2015) POLAR - Participation of Local Areas. [Online]. Available at http://www.hefce.ac.uk/analysis/yp/POLAR/(accessed 13 September 2015)

HEFCE. (2016) Map of young participation areas. [Online]. Available at: http://www.hefce.ac.uk/analysis/yp/POLAR/Map,of,young,participation,areas / (Accessed 5 April 2016)

Johnson, M. \& Lewis, C. (2013) 'Can you dig it?’ Developing an approach to validly assessing diverse skills in an archaeological context. Journal of Vocational Education \& Training, 65, 2): 177-192.

Jørgensen, C.H. (2004) 'Connecting work and education: Should learning be useful, correct or meaningful?’ The Journal of Workplace Learning, 16, 8: 455-465.

Kirkpatrick, D.L. (1994) Evaluating training programs: The four levels. San Francisco: Berret-Koehler.

Knowles, J. (2012) ‘Aimhigher and Deserted Medieval Villages’ in G Moshenska and S Dhanjal (eds) Community Archaeology: Theory, Methods and Practice. Oxford: Oxbow Books. pp 63-70. 
Laker, D.R., and Powell, J.L, (2011) 'The differences between hard and soft skills and their relative impact on training transfer'. Human Resource Development Quarterly 22, 1: 111-122.

Lewis, C., Mitchell-Fox, P. and Dyer, C. C. (1997) Village, Hamlet and Field, Manchester: Manchester University Press.

Lewis, C. (2003) 'Test Pitting medieval settlements - Big Dig 2003’. Medieval Settlement Research Group Annual Report 18: 46-48.

Lewis, C. (2007) 'New avenues for the investigation of currently-occupied rural settlement - preliminary observations from the Higher Education Field Academy’. Medieval Archaeology, 51, 1: 133-164.

Lewis, C. (2011). Higher Education Field Academy: Report 2009 \& 2010. Cambridge: University of Cambridge Department of Archaeology. [Online]. Available at:

http://www.access.arch.cam.ac.uk/schools/hefa/HEFA\%20Report\%20200910.pdf (accessed 12 October 2016).

Lewis, C. (2014a) 'The Power of Pits: Archaeology, outreach and research in living landscapes' in K. Boyle, R. Rabett and C. Hunt (eds) Living in the Landscape. Cambridge: McDonald Institute for Archaeological Research Monograph. pp 321-338.

Lewis, C. (2014b). 'Cooler than a trip to Alton Towers': Assessing the impact of the Higher Education Field Academy 2005-2013' in Public Archaeology, 13, 4: 295-322.

Lewis, C. (2014c) Higher Education Field Academy Annual Report 2013-14. Unpublished report to University of Cambridge Admissions Office (Widening Participation).

Lewis, C. (2015) Higher Education Field Academy Annual Report 2014-15. Unpublished report to University of Cambridge Admissions Office (Widening Participation).

Lewis, C. (2016) 'Disaster Recovery? - New archaeological evidence from eastern England for the impact of the 'calamitous' $14^{\text {th }}$ century' Antiquity, 90, 351: 777-797. DOI: http://dx.doi.org/10.15184/aqy.2016.69

McCaig, Colin. (2015) 'The Impact of the Changing English Higher Education Marketplace on Widening Participation and Fair Access: Evidence From a Discourse Analysis of Access Agreements.' Widening Participation and Lifelong Learning 17, 1: 5-22 doi.10.5456/WPLL.7.1.5.

Milburn, A. (2012) University Challenge: How Higher Education Can Advance Social Mobility. A progress report by the Independent Reviewer on Social Mobility and Child Poverty. [Online]. Available at: https://www.gov.uk/government/uploads/system/uploads/attachment_data/file /80188/Higher-Education.pdf (accessed 22 Oct 2016)

National Curriculum. (n.d). Personal, learning and thinking skills. [Online]. Available at: 
http://webarchive.nationalarchives.gov.uk/20110223175304/http:/curriculum. qcda.gov.uk/key-stages-3-and-4/skills/personal-learning-and-thinkingskills/index.aspx (accessed 26 Nov 2015).

Neary, M. and Winn, J. (2009) 'The Student as Producer: reinventing the student experience in higher education', in L.Bell, H. Stevenson, M.Neary (eds.) The Future of Higher Education: Policy, Pedagogy and the Student Experience, London: Continuum.

OFFA. (2014) Trends in Young Participation by student background and selectivity of institution. Bristol: OFFA. [Online], available at https://www.offa.org.uk/wp-content/uploads/2006/07/OFFA-2014.01.pdf (accessed 12 Oct 2016)

OFFA. (2015) Access agreements for 2016-17: key statistics and analysis. Bristol: OFFA. [Online], available at https://www.offa.org.uk/wpcontent/uploads/2015/07/Access-agreements-for-2016-17-key-statistics-andanalysis.pdf (accessed 26 Nov 2015)

Passy, R. and Morris, M. (2010) Evaluation of Aimhigher: learner attainment and progression. Report by National Foundation for Educational Research [Online], available at: http://www.hefce.ac.uk/media/hefce/content/pubs/2010/rd1510/rd15 10.pdf (accessed 26 Nov 2015).

Piaget, J. (1963) Origins of intelligence in the child. London: Routledge and Keegan Paul

Praslova, L. (2010) ‘Adaptation of Kirkpatrick’s four level model of training criteria to assessment of learning outcomes and program evaluation in Higher Education'. Educational Assessment, Evaluation and Accountability, 22, 3: 215-225. doi: 10.1007/s11092-010-9098-7

Rainford, J. (2016) 'Targeting of widening participation measures by elite institutions: widening access or simply aiding recruitment?’ Perspectives: Policy and Practice in Higher Education, DOI: $\underline{10.1080 / 13603108.2016 .1148645}$

Raphael Reed, L. R., Croudace, C., Harrison, N., Baxter, A. and Last, K. (2007) Young Participation in Higher Education: a sociocultural study of educational engagement in Bristol South parliamentary constituency. Bristol, The University of the West of England.

Shuman, L.J., Besterfield-Sacre, M. and McGourty, J. (2005) 'The ABET 'professional skills' - can they be taught? Can they be assessed?' Journal of Engineering Education 94, 1: 41-55.

Stone, J. (2013) Fakenham High School and College: Higher Education Field Academy (HEFA) 2012 Feedback and Impact Summary. Cambridge: Unpublished report: Access Cambridge Archaeology

Stuart, M. (2012) Social Mobility and Higher Education: The Life Experiences of First Generation Entrants in Higher Education. London: Institute of Education. 
Thomas, L. (2001) Widening Participation in Post-compulsory Education. London: Continuum.

Thomas, L. (2012) Building student engagement and belonging in Higher Education at a time of change: a summary of findings and recommendations from the What Works? Student Retention \& Success programme. London: Paul Hamlyn Foundation

University of Cambridge. (2013). Using Medieval Village Research to Improve the Skills and Aspirations of Secondary School Students and Disadvantaged Adults. Impact Case Study submitted to the 2014 REF. [Online], available at http://impact.ref.ac.uk/CaseStudies/CaseStudy.aspx?Id=17858 (accessed 26 Nov 2015).

Watkins, R., Leigh, D., Foshay, R. \& Kaufman, R. (1998). 'Kirkpatrick plus: Evaluation and continuous improvement with a community focus'. Educational Technology Research and Development. December 1998, 46, 4: 90-96. doi:10.1007/BF02299676 